Latorre Romero, Amparo.

Cultore della materia in Storia dell'arte contemporánea. Dipartimento di Storia dell'arte e spettacolo. Sapienza Università di Roma.

\title{
La utilización del cuerpo abyecto. De la mujer real y virtual en el arte.
}

\author{
TIPO DE TRABAJO
}

Comunicación.

PALABRAS CLAVE

Arte, cuerpo, abyecto, mujer, virtual.

KEY WORDS

Art, body, abject, woman, virtual.

\section{RESUMEN}

Nunca una sociedad se había visto tan inmersa en perseguir estereotipos corporales y de éxito, más allá de la ética, comprendida y aplicada hasta ahora. Acrecentada, aún más si cabe, con el sentido de pertenencia a un cierto tipo de estética corporal e ideológica.

Se observa en el cuerpo el anhelo de la comunicación verdadera, el entendimiento y la pertenencia a un mundo que pone continuamente espejos delante del cuerpo. Consideramos, en este caso, el cuerpo como enemigo, que no queremos que sea observado o plasmado de ninguna de las maneras.

La relación de la mujer con la abyección es extrañamente contradictoria: se lleva mal con el cuerpo materno, pero no así con la idea de ser madre. Este concepto se explica particularmente bien en el libro Poderes del horror, de Julia Kristeva. Para ella, la comida es el objeto -abyecto- oral que se opone al yo, la relación de uno mismo con los otros.

El objetivo de esta comunicación es reflexionar sobre la utilización del cuerpo abyecto de la mujer real y virtual en el arte.

\section{ABSTRACT}

Never a society had been so immersed in stereotypes and pursue personal success, beyond ethics, understood and applied so far. Increased even more if possible, with a sense of belonging to a certain type of body and ideological aesthetics.

It is observed in the body the yearning for true communication, understanding and belonging to a world that continually puts mirrors in front of the body.

We consider, in this case, the body as an enemy, we do not want to be seen or captured in any way.

The relationship of women with abjection is strangely contradictory, takes wrong with the mother's body, but not with the idea of being a mother. This concept is explained particularly well in the book Powers of Horror, Julia Kristeva.

As she points out the food is the oral-abject- object opposes me, the relationship between oneself and others.

The aim of this paper is to reflect on the use of the abject body of real and virtual women in art.

\section{CONTENIDO}

Virtual, (del latín virtus, fuerza, virtud). Que tiene virtud para producir un efecto, aunque no lo produce de presente, frecuentemente en oposición a efectivo o real. Es aquello que tiene existencia aparente y no es real.

Real, (del latín res, rei, traducible por cosa), un concepto filosófico, psicológico y epistemológico con diverso grado de relación con el concepto coloquial de realidad. Real es aquello que existe de manera verdadera o auténtica. Lo real pertenece al plano de la realidad. 
El cuerpo en el arte, como estudio es un tema muy vasto, que conviene delimitar y definir en las investigaciones para poder ahondar sin perderse en sus anfibologías. Es nuestra conexión con el mundo:

«El cuerpo es y será la medida en la comprensión del mundo que nos rodea sin importar la evolución en los medios y sus nuevas tecnologías en continuo cambio. Su tarea parece consistir en brindar el primer paso en el principio organizador del conocimiento individual de cada ser humano. Las preguntas que la semiótica se ha planteado en consecuencia van en estrecha relación con la concepción sígnica y textual que parte del cuerpo en tanto que proceso de lectura sensorial y patémica en primera instancia, y ética y cognitiva en una fase ulterior, que daría respuesta a la transformación de la sentencia senso ergo sum, en una pregunta». ${ }^{1}$

El "siento luego existo" de Hume, en oposición al "cogito ergo sum" - "pienso luego existo" de Descartes. La capacidad de sentir del cuerpo es una de sus características que sin duda nos acercan a lo real.

"El cuerpo" es, en realidad, una abstracción; hay cuerpos de mujeres y de ancianos, cuerpos seropositivos y cuerpos que se rentan a la luz de las nuevas tecnologías de la reproducción. [...] la otra lección o al menos constatación es que las identidades personales y colectivas están o son necesariamente encarnadas.» ${ }^{2}$

Considero oportuno explicar que el concepto, de abyección para después aplicarlo a su máxima representación en el cuerpo de la mujer.

La abyección, según Kristeva, es: "lo que perturba identidad, sistema y orden. Lo que no respeta bordes, posiciones, reglas."

¿Qué podemos encontrar más semejante a esta definición que el cuerpo de la mujer gestante?

Tanto espacial como temporalmente, la abyección es la condición en la cual la identidad se encuentra perturbada, donde se produce un colapso del significado.

¿Sería posible aunar el terror, el cambio, lo interno-externo, el placer-el dolor, las fantasías, los miedos, los fluidos, la materia, la expansión-la retracción, la inserción-la expulsión, cuerpo conquistado y cuerpo abandonado, duelo por separación y existencia fuera del cuerpo?

La respuesta sería que todo esto se podría contener en un cuerpo gestante, madre omnipotente capaz de contener dos sexos: masculino y femenino.La Diosa Madre, reine sprache, lengua pura, lengua madre.

En ese cuerpo, he estado yo. Compartir una coidentidad, simbiosis, díada, fusión, mezcla con otro cuerpo tan cercano como lejano, la primera morada.

El niño abandona el cuerpo de la madre cuando nace. Es una acción traumática. A la vez que real.

Sin embargo cuando la imagen de la mujer y su cuerpo abyecto que es el tema en el que nos ocuparemos en esta comunicación quedan plasmadas en el arte, sobre todo en el S. XXI observamos representaciones: estereotipadas, construidas, sublimadas, forzadas.

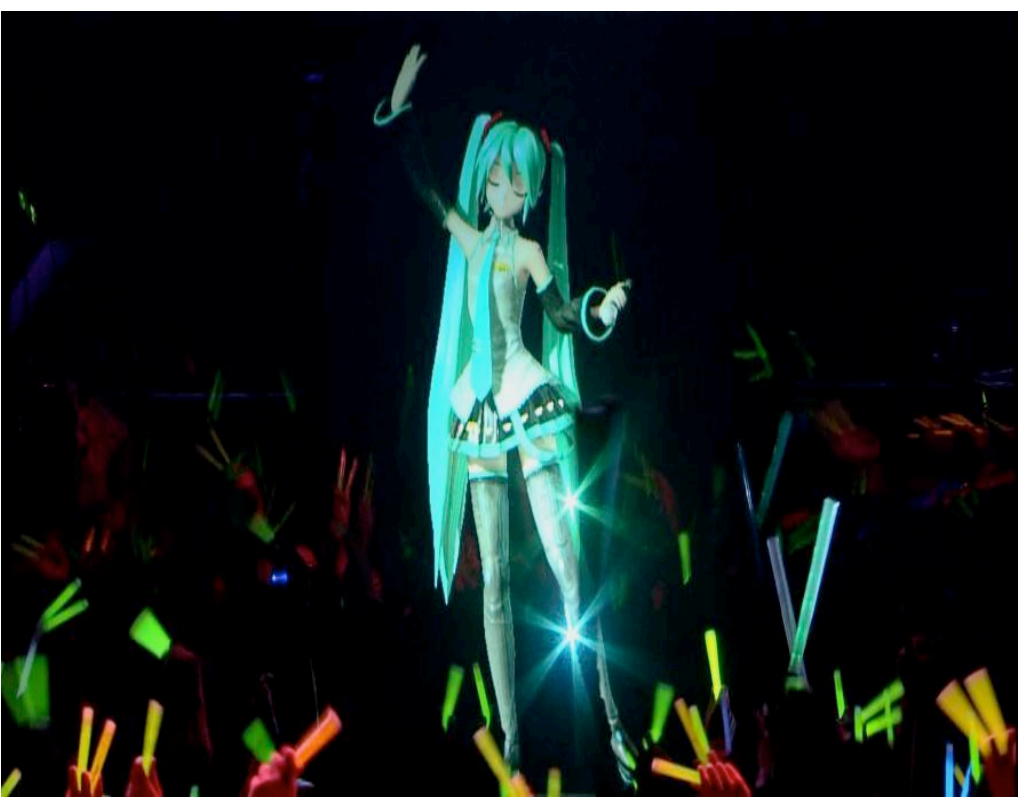

llustración 1.

Cantantes virtuales llenan estadios en Japón, como el holograma virtual, llamada cantante de pop Hatsune Miku, con su Dilidala (Eva's Polka). Miku es un programa informático.

En sentido estricto, es sólo la primera voz de la heroína de una serie de Vocaloid2 Character Vocal Series, publicada el 31 de agosto de 2007 por Crypton Future Media. La 'voz' de Miku fue creada basándose en la voz de la actriz japonesa Saki Fujita.

\footnotetext{
${ }_{1}^{1}$ Olavarría, María Eugenia. Cuerpo(s): sexos, sentidos, semiosis. Buenos Aires: La Crujía Ediciones, 2010.

${ }^{2}$ Bähler, Ursula y otros. El cuerpo figurado. "Tópicos del Seminario 16". México: Benemérita Universidad Autónoma de Puebla, 2006, p. 146 .
} 
Quién hubiera pensado, creo que ni siquiera el creador de la holografía Dennis Gabor, que una de sus criaturas sustituiría a un ser humano en el escenario.

El discurso es que se está realizando la apropiación de un cuerpo visualmente, que no se cansa, no se lamenta, no tiene límites.

Pero al mismo tiempo es totalmente manipulable, adaptable, cómodo, manejable, adulterable, maleable.

De ese modo la grandeza moral y ética del cuerpo se desvanece como entidad de medida y conocimiento del mundo. Entra en conflicto claramente con la tipología abyección de Kristeva.

Al fenómeno que asistimos es a la regulación del cuerpo, convirtiéndolo en un símbolo y apartándolo de la realidad. Estamos creando un tótem, en terminología freudiana, con sus tabúes, tratando de borrar sus fragilidades, su condición de mamífero, su pragmatismo.

Queremos crear un cuerpo emancipado de nosotros mismos y bajo nuestro control, ¿̇no es acaso un reflejo de la crisis de la medicina y la sociología y sus vanos intentos por controlarlo?

La abyección es crónica, no se puede borrar y no es una afección.

Eso sí que difiere de la visión hedonística y libertaria que quiere ofrecer la sociedad. Chris Shilling, en su libro "The Body in Culture, Technology and Society" además de especificarnos claramente que el cuerpo tiene unas connotaciones adquiridas, especialmente en la sociedad occidental, nos explica cómo las sociedades construyen el género del cuerpo para poder entenderlo y clasificarlo mejor.

El cuerpo tiene una identidad propia además de una identidad social. La interdependencia social de los cuerpos está unida irreductiblemente a la identidad personal.

El cuerpo es mutante y cambiante; todos los días nacen y mueren miles de células. Existe una clara demarcación entre el cuerpo social y el cuerpo natural.

El individuo filtra y racionaliza las reglas para vivir en sociedad.

Louis Wirth decía que la enfermedad de una persona solo podía ser entendida en un contexto social completo. Para Gabriel Marcel: yo soy mi cuerpo, que es mi principal sentido de posesión y control. Desde la perspectiva foucaltiana, la medicina y la sociología van unidas; la sociología del cuerpo es fundamental en el estudio médico. El cuerpo no es objeto ni instrumento. Para Sartre el cuerpo es nuestro contacto con el mundo. La posesión de un cuerpo a pesar de sus problemas es una rutina esencial de identificación y separación de personas.

Como decían los romanos, persona perpetua, pero los esclavos no eran dueños de su cuerpo, lo era su señor. Persona ficta-persona universalis- una persona compuesta de varias. Sociológicamente y filosóficamente se ha dado por supuesto que el cuerpo es un organismo inanimado. (Es una discusión a menudo recurrente). Pronto se desmonta esta teoría, por ejemplo, en la época medieval el rey tenía dos cuerpos: uno real y corruptible, y otro ficticio e inmortal. El cuerpo sagrado e inmortal del rey garantizaba la unidad y la continuidad de la sociedad.

Sin embargo, un ataque al rey era sobre su persona y sobre toda la sociedad. Esto también se aplica a los héroes: mítica es la leyenda del Cid, que a lomos de Babieca ganaba batallas muerto. Los cuerpos femeninos son muy fuertes: producen alimento, sangran y no mueren.

Desde un punto de vista sociológico es normal que una persona tenga dos cuerpos, porque el cuerpo es una entidad y un signo.El cuerpo ha sido dominado desde siempre por la sociedad a la que ha pertenecido y por el credo, sea cual fuere. En la religión católica, por ejemplo, en el Génesis el Señor le dijo a la mujer: «Mucho te haré sufrir en tu preñez, parirás hijos con dolor, tendrás ansia de tu marido y él te dominará.»

El cuerpo de la mujer encarna y personifica el cuerpo del dolor, ese cuerpo en espera para el dolor mayor que será el parto. Es un cuerpo sexuado, tiene aquellas características que le pertenecen a su condición. La menstruación forma parte de la identidad del cuerpo femenino. Y en la sociedad occidental patriarcal se toma esto como partido para clasificar a la mujer.En cuanto esta cesa en su papel procreador, la sociedad la aparta del esquema de cuerpo útil.

Citando el título de un capítulo del libro de Pilar Pedraza titulado La bestia más bella:

“Ese ser mamífero que continuamente está renovando su sangre, representación por antonomasia de vida y muerte.

Una imagen absolutamente dicotómica, un ser que pierde sangre y no muere; todo un misterio de su condición humana".

Esta complejidad está ligada indisociablemente al cuerpo de la mujer. Este fenómeno biológico se convierte en un significante de diversidad con un significado de sintomatología abyecta, la cual no es muy prolífica representacionalmente.

Este signo de diversidad está unido culturalmente a una sucesión de intentos de ocultación.

"La Máquina de Menstruar simula el dolor y el sangrado promedio de cinco días de menstruación humana". Es decir, calcularon, unos 80 mililitros. $^{3}$

\footnotetext{
${ }^{3}$ [en línea], http://www.revistaenie.clarin.com/arte/maquina-menstruar-arte-dolor_0 431956984.html (Consulta: 13/02/2013).
} 


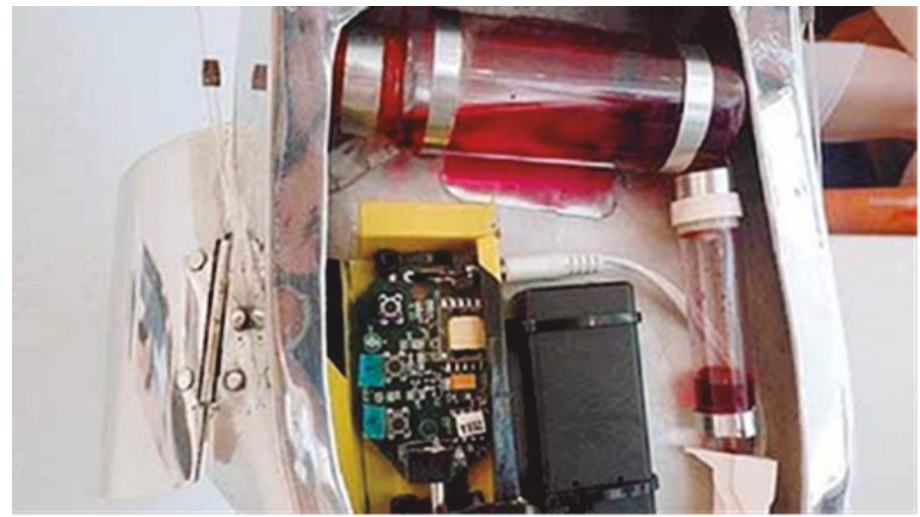

Ilustración 2.

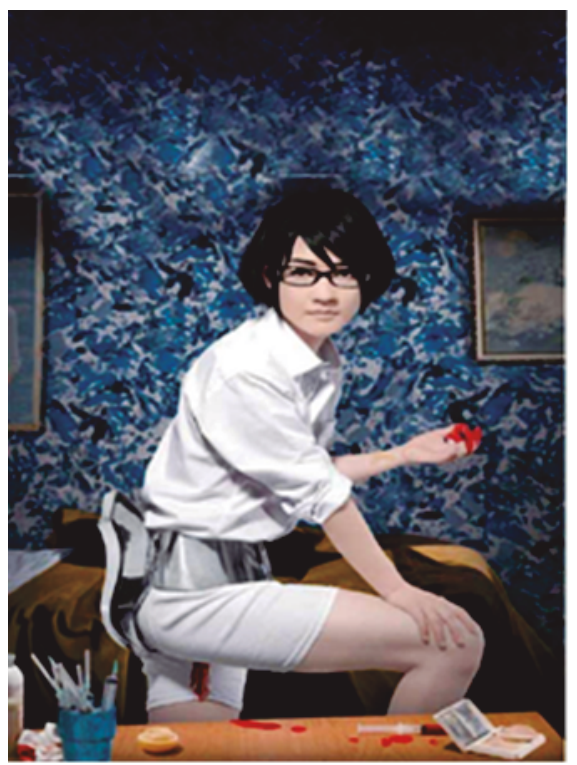

Ilustración 3. La artista japonesa Hiromi Ozaki

Da lugar a la autorreferencia por parte de artistas femeninas.

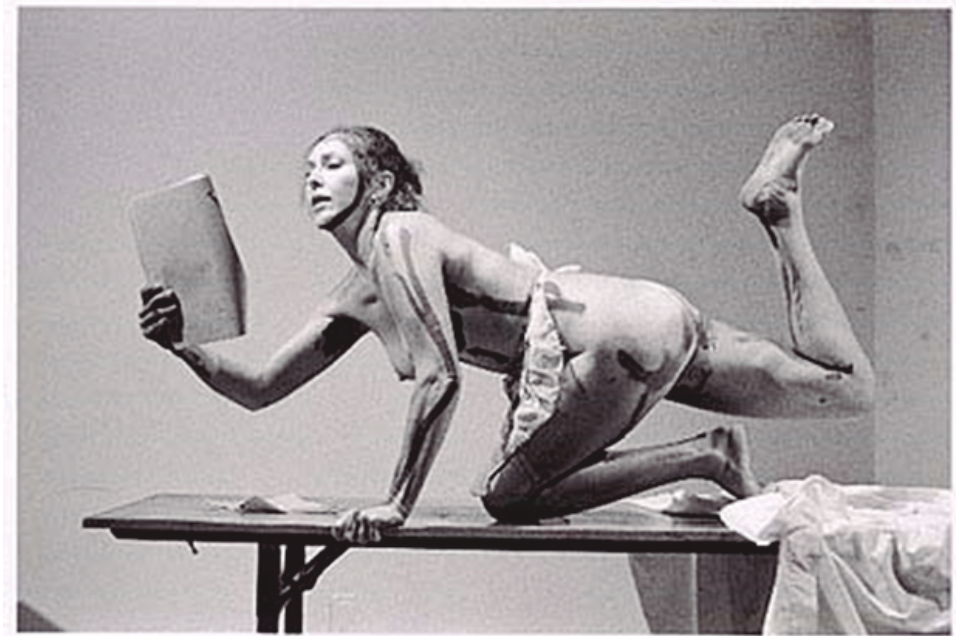

Ilustración 4. Imágenes de la performance de Carolee Scheneemann Interior Scroll (1976). ${ }^{4}$

\footnotetext{
${ }^{4}$ Kim, Painter. Menstruation: Cycle of pain or creativity? USATODAY (Consulta: 6/10/2007).

[enlínea],http://usatoday30.usatoday.com/news/health/painter/2007-06-10-yourhealth_N.htm (Consulta: 13/02/2013).
} 
Extrae de su vagina un rollo, manifestando el simbolismo del cuerpo femenino. Siempre tras el anhelo de ser interpretado, estudiado, escuchado.

La idea fundamental que encierra el concepto de la abyección es que sirve para cruzar los límites, jugar con las prohibiciones, más concretamente, la transgresión.

La abyección es humana, en su función corporal lo abyecto regula y sostiene. Se deshace de lo sobrante y permite que el cuerpo viva. Es polifacética e inabarcable. La perspectiva es diferente según se observe a partir de su presente histórico o a partir de una evolución todavía inacabada.

Es cíclico, repetitivo y paradójico. Así, el cuerpo de la mujer embarazada es su máxima representación, la mujer madre omnipotente capaz de contener dos sexos: masculino y femenino, a pesar de que se ha considerado a la mujer biológicamente frágil, con el cuerpo i Socialmente se acepta la construcción de un cuerpo irreal. Es un cuerpo simbólico lejos de enfermedades y bajo las presiones de la inserción frente a la sociedad y al sueño de la dominación jerárquica, además del poder/placer de las sociedades tecnológicas. Volviendo a la idea del ciborg de los 70 y 80 , un cuerpo transhumano y modular, sin dolor, híbrido, interfaz, la bioingeniería entronca con la idea del límite corporal. Pues el ciborg se sitúa en la parcialidad, la perversidad. No es nada inocente, ni el lenguaje, ni el comportamiento social hacen una separación convincente.

Con respecto a la cientificidad del cuerpo humano tiene puntos de ruptura. Es el resultado de fronteras transgredidas, fusiones poderosas y posibilidades infinitas. Es una apostasía del mito y la identificación, una lucha de fronteras entre ciencia ficción y realidad social. Este concepto se explica muy bien con la teoría del "biopoder" de Michel Foucault. Imperfecto y construída de los desechos del hombre.

Por ello entendemos que la utilización del cuerpo de la mujer abyecto tanto real como virtual en el arte sigue siendo una readaptación anfibológica de combinaciones infinitas, tantas como el arte en sí mismo.

\section{FUENTES REFERENCIALES}

Bibliografía

BÄHLER, Ursula .El cuerpo figurado. "Tópicos del Seminario 16". México: Benemérita Universidad Autónoma de Puebla, 2006.

FOUCAULT, Michel. Tecnologías del yo y otros textos afines. Pensamiento Contemporáneo. Madrid: Paidós, 1990.

FOUCAULT, Michel. Las palabras y las cosas. Una arqueología de las ciencias humanas. Madrid: Siglo XXI, 2006.

FOUCAULT, Michel. Una lectura de Kant. Introducción a la antropología en sentido pragmático. Siglo XXI, 2009.

KRISTEVA, Julia. Powers of horror. Ann Essay on Abjection. New York University Press, 1982.

MILLER, Alice. El cuerpo nunca miente. Tusquets Editores, 2005

MILLER, William Ian. Anatomía del asco. Madrid: Taurus, 2000.

OLAVARRÍA, María Eugenia y otros. Cuerpo(s): sexos, sentidos, semiosis. Buenos Aires: La Crujía Ediciones, 2010.

PEDRAZA, Pilar. Bella, enigma y pesadilla. (Esfinge, Medusa, Pantera).Tusquets Editores, Ensayo, 1991.

SHILLING, Chris. The Body ans Social Theory. London: Sage Publications, 1993.

SHILLING, Chris. The Body in Culture, Technology and Society. London: Sage Publications, 2005.

SHILLING, Chris. Embodying Sociology: Retrospect, progress and prospects. London: Blackwell, 2007.

Sitografía

Kim, Painter. Menstruation: Cycle of pain or creativity? USATODAY (Consulta: 6/10/2007).

[enlínea],http://usatoday30.usatoday.com/news/health/painter/2007-06-10-yourhealth_N.htm (Consulta: 13/02/2013). 